\title{
Blade Tip Leakage Flow and Heat Transfer with Pressure-Side Winglet
}

\author{
A. K. Saha, ${ }^{1,2}$ Sumanta Acharya, ${ }^{1}$ Ron Bunker, ${ }^{3}$ and Chander Prakash ${ }^{4}$ \\ ${ }^{1}$ Turbine Innovation and Energy Research (TIER) Center, Louisiana State University, Baton Rouge, LA 70803, USA \\ ${ }^{2}$ Department of Mechanical Engineering, Indian Institute of Technology Kanpur, Kanpur, 208 016, UP, India \\ ${ }^{3}$ General Electric Global Research, Niskayuna, NY 12309, USA \\ ${ }^{4}$ General Electric Aircraft Engines, Cincinnati, $\mathrm{OH} 45215$, USA
}

Received 11 October 2005; Accepted 20 February 2006

\begin{abstract}
A numerical study has been conducted to explore the effect of a pressure-side winglet on the flow and heat transfer over a blade tip. Calculations are performed for both a flat tip and a squealer tip. The winglet is in the form of a flat extension, and is shaped in the axial chord direction to have the maximum thickness at the chord location, where the pressure difference is the largest between the pressure and suction sides. For the flat tip, the pressure-side winglet exhibits a significant reduction in the leakage flow strength. The low heat transfer coefficient "sweet-spot" region is larger with the pressure-side winglet, and lower heat transfer coefficients are also observed along the pressure side of the blade. For the flat tip, the winglet reduces the heat transfer coefficient locally by as much as $30 \%$, while the average heat transfer coefficient is reduced by about $7 \%$. In the presence of a squealer, the role of the winglet decreases significantly, and a 5\% reduction in the pressure loss coefficient is achieved with the winglet with virtually no reduction in the average heat transfer coefficient. On the other hand, the suction-side squealer with constant width winglet shows lower heat transfer (reduction of 5.5\%) and pressure loss coefficient (reduction of 26\%) than its baseline counterpart.
\end{abstract}

Copyright $\odot 2006$ A. K. Saha et al. This is an open access article distributed under the Creative Commons Attribution License, which permits unrestricted use, distribution, and reproduction in any medium, provided the original work is properly cited.

\section{INTRODUCTION}

In the development of modern high-performance gas turbines, reduction of aerodynamic losses and thermal loading to the blades are two key areas targeted for improvement. The blade tip requires particular attention since the highest thermal loads typically occur in this region, and blades are most susceptible to failure along the tip. In rotor blades, a clearance gap exists between the blade tip and the stationary outer shroud. Thus, under normal operation, the pressure difference between the pressure and suction sides of the blade drives a leakage flow across the tip, resulting in a strongly accelerating flow through the gap. This has detrimental effects on both the aerodynamic performance and heat transfer. In addition, the interaction of the tip leakage flow and the main passage flow results in the generation of a secondary leakage vortex on the suction side of the blade. Due to the radial migration of the temperature, the leakage flow entering the gap is close to the peak temperatures in the hot gas path (Mayle and Metzger [1]; Metzger and Rued [2]). Consequently, the thermal loading at the blade tip is very significant, and is particularly severe near the trailing edge as this zone is difficult to cool with conventional internal cooling flows. It has been estimated that the turbine efficiency decreases by $1-2 \%$ for every $1 \%$ increase in tip clearance (Booth et al. [3]). Details about the tip leakage flow, and its structure, have been reported by a number of investigators including Sieverding [4], Bindon [5], Moore and Tilton [6], and Bunker [7].

In view of the increased aerodynamic loss and high thermal loading associated with the leakage flows, considerable effort has been spent by turbine designers in developing strategies for reducing tip leakage. The most commonly used technique for reducing tip leakage flow and tip heat transfer is the use of squealer tips. In a recent review paper, Bunker [7] reports most of the work related to squealer tips and has provided a detailed discussion on the key aerodynamic and thermal issues related to the blade tip region. The squealer tip essentially works like a labyrinth seal and increases the resistance to the flow through the tip gap thus reducing the leakage flow. Further, since only the squealer rim is in close proximity of the shroud, occasional rubbing of the tip does not lead to severe damage or catastrophic failure of the whole blade system as in the case of a flat tip blade. Therefore, the use of squealer tip allows lower tip clearances to be used, which reduces the leakage flow and lowers the heat transfer 
to the blade tip. Heyes et al. [8] studied tip leakage on flat and squealer tips, in a linear cascade environment, and observed that suction-side squealers are the most effective in reducing leakage flows. Yang and Diller [9] measured local heat transfer coefficient on a squealer blade tip model for different tip clearances in a cascade wind tunnel, and did not observe any strong sensitivity of the tip heat transfer to the clearance gap and Mach number. Their observation is based on data taken with a single heat flux gage on the tip. Ameri et al. [10] and Ameri and Bunker [11] performed a numerical study, while Bunker et al. [12] performed experiments on the flow and heat transfer for a flat and squealer tip GE-E ${ }^{3}$ blade. They also reported significant reductions in tip heat transfer with squealer tips. More recently, Yang et al. [13, 14] and Azad et al. [15] have reported comparisons between flat and squealer tip GE-E $\mathrm{E}^{3}$ blade, and also conclude that significant reductions in tip heat transfer rates are achieved with squealer tips.

To achieve further reductions in the leakage flow and tip heat transfer coefficients, geometric modifications of the blade tip have been explored to alter the flow characteristics in the tip gap region. Such efforts directed toward reducing the leakage flows have been termed tip desensitization. Example of such desensitization studies include (i) addition of tip winglets (Harvey and Ramsdan [16]; Dey and Camci [17]); (ii) modification of the tip blade profile (Bindon and Morphis [18]); (iii) incorporating a nonuniform tip gap in the direction normal to the blade surface (Tallman and Lakshminarayana [19]); (iv) normal/angled injection of fluid into the squealer tip regions (Chen et al. [20]); and (v) generation of high intensity turbulence upstream of the rotor for weakening the tip vortex (Staubach et al. [21]). These desensitization strategies have shown the potential benefits of such an approach, but additional work is needed to explore their range of applicability, and to optimize the benefits from the desensitization approach.

In the recent past, a number of studies have explored the use of winglets to determine if they are effective in reducing the tip leakage flow. Harvey and Ramsdan [16] have reported a computational study in which large winglets on both pressure and suction sides (termed partial shroud) were used. The partial shrouds are shown to increase efficiency by $1.2-$ $1.8 \%$ for a tip gap of $2 \%$ of the blade height. Booth et al. [3] investigated various winglet designs and obtained an improvement of $0.6 \%$ of rotor efficiency at a tip clearance of $3 \%$. Similarly,Bindon and Morphis [18] carried out a study using winglet on pressure and suction sides, separately and together, and achieved a reduction of $10 \%$ of tip leakage flow. In their study, there is also a decrease in stage efficiency of $0.35 \%$ at $1.7 \%$ tip gap. Most recently, Tallman and Lakshminarayana [19] reported a numerical study on tip desensitization by chamfering the blade tip. They explored three modifications to the tip: (i) leading edge chamfer, (ii) trailing edge chamfer, and (iii) full blade tip chamfer. Comparison of the three cases was made with respect to the baseline case of flat tip without chamfer. Their study shows that the trailing edge chamfering reduces the tip leakage vortex, while leading edge chamfering increases the strength of the tip leakage vortex. An experimental study by Dey and Camci [17] reports the effect of tip desensitization through the use of winglets on the flow characteristics for an axial turbine blade. Winglets of different widths and geometrical profiles on the pressure and suction sides were tested to desensitize the tip. They also varied the tip gap. Comparisons were made with baseline experiments having a flat tip. Their results show that the suction-side winglets are not effective, while the pressure-side winglets alter the tip leakage considerably. Since their study does not involve heat transfer, they could not evaluate the effectiveness of the desensitization scheme in reducing the tip heat transfer. In a recent study, Papa et al. [22] carried out mass transfer experiments on normal and desensitized squealer tip geometry. The tip geometry considered is a winglet on the pressure side and a squealer on the suction side. The desensitized case has been compared with the baseline squealer tip, with pressure and suctionside squealers. Measurements were reported for various tip clearance (0.6-3.6\% of actual chord) and a single Reynolds number of $7.2 \times 10^{5}$. A significant difference in mass transfer is observed with tip clearance for the squealer tip while the winglet-squealer is not sensitive to the tip gap. At higher tip clearances, the winglet-squealer combination is shown to lead to lower tip heat transfer rates relative to the full squealer case. However, no effort was made to measure or compare the aerodynamic loss with the two configurations, and no details of the flowfield were presented.

In the present paper, the effect of a pressure-side winglet on both the leakage flow and the tip heat transfer rate are explored computationally. The calculations are performed for a scaled up model of a typical high-pressure-turbine (HPT) rotor blade. Since suction-side winglets have been shown not to be effective [17] in improving the turbine performance, in the present paper, desensitization studies have been based on a pressure-side winglet only. The majority of the calculations are with the winglet shaped based on the pressure difference between the pressure and suction sides of the baseline flat tip case, and is therefore thickest at the location of the largest pressure difference. Calculations are reported for the following cases.

(1) Flat tip with and without pressure-side winglet.

(2) Full squealer tip with and without pressure-side winglet.

(3) Suction-side squealer with and without pressure-side winglet.

(4) Suction-side squealer and a constant width and thicker pressure-side winglet than the case 3 .

The schematics of the different cases are shown in Figure 1. In all the cases, except the constant width winglet, the maximum width $(\mathrm{w})$ of the winglet is about $4.75 \%$ of the blade span. The thickness (s) of the winglet is $2 \%$ of the blade span. Only one clearance gap of $1 \%$ of the blade span is studied. If the width (w) and the thickness (s) are expressed in terms of the tip gap, they are 4.75 and 2.0 times as that of tip gap, respectively. For the squealer geometry, the depth of the squealer cavity is 5.0 times while the rim thickness is 1.75 times of the tip clearance. Since the blade is assumed to be 


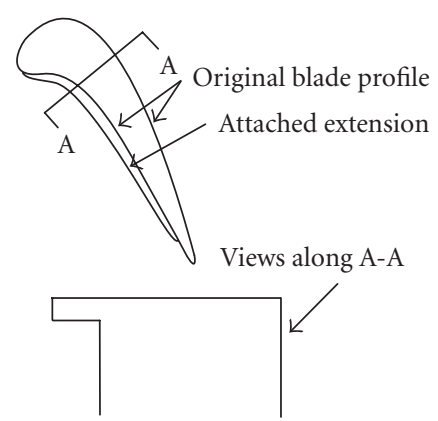

(a)

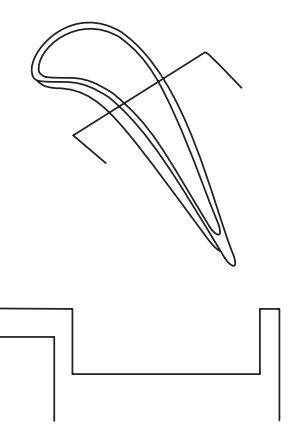

(b)
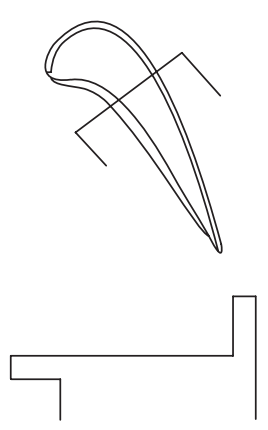

(c)

FIGURE 1: Schematics of (a) flat tip with winglet, (b) squealer tip with winglet, and (c) suction-side squealer with winglet.

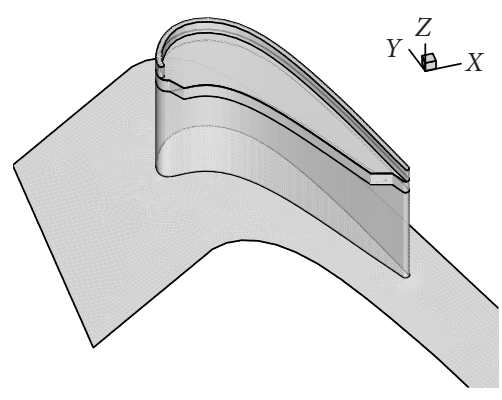

(a)

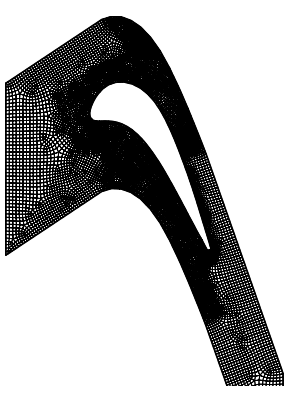

(b)

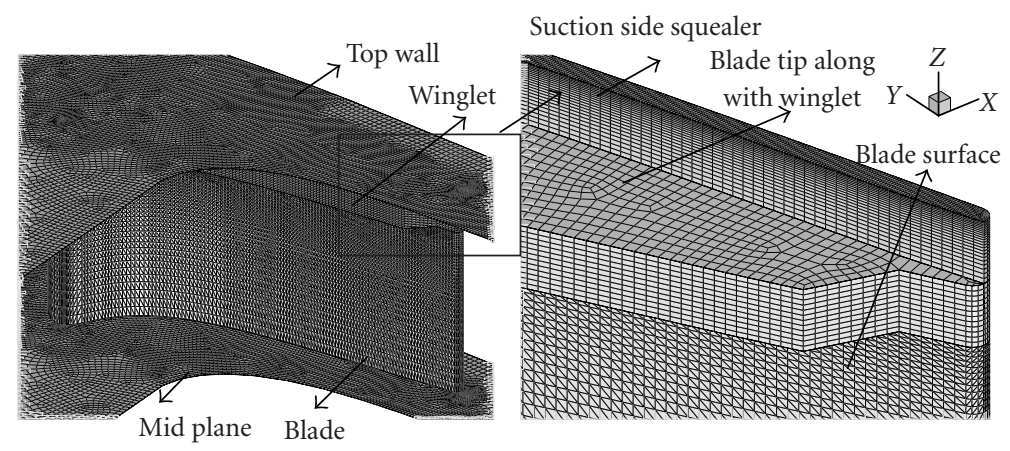

(c)

FIGURE 2: (a) Geometry of the model, (b) grid distribution at the mid-span, and (c) three-dimensional view of the grid and zoomed-in view near the suction-side squealer tip with winglet.

at constant temperature, no heat conduction is solved for the solid blades.

\section{COMPUTATIONAL DETAILS}

All the simulations in the present study were carried out using a commercial software called FLUENT. The three-dimensional compressible Reynolds-Averaged Navier-Stokes equations are solved using a finite volume formulation to discretize these equations. An unstructured grid is generated using a grid-generation software called GAMBIT with grid clustering near the blade wall and the tip regions. Figure 2 depicts a schematic of the blade geometry, the computational domain (Figure 2(a)), and a typical grid (through the midspan of the blade) used in the calculations (Figure 2(b)). An additional three-dimensional view of the grid along with an exploded view near the tip region is shown in Figure 2(c), and reveals the complexity of the grid involved in the present study.

The scaled-up blades have a constant axial chord length of $6.64 \mathrm{~cm}$ and aspect ratio (span to chord) of 1.53 . The blade leading edge pitch is $9.41 \mathrm{~cm}$. For the results presented in 
this paper, the inlet of the computational domain is placed at about 0.8 times the axial chord from the leading edge while the outlet is located at 1.7 times the axial chord from the trailing edge to have smooth transition of the flow at the outlet.

The computations were carried out using one blade with periodic boundary conditions imposed along the boundaries in the circumferential (pitch) direction. At the inlet, a total temperature of $300 \mathrm{~K}$ and pressure of $175.182 \mathrm{KPa}$ are specified along with an inlet flow angle and turbulence intensity of $-6.75^{\circ}$ and 5\%, respectively. This corresponds to a Reynolds number of $2.22 \times 10^{5}$, based on axial chord length and axial velocity. At the exit, a static pressure of $101.325 \mathrm{KPa}$ was used thus giving an overall pressure ratio of 1.73 across the blade. No-slip velocity boundary conditions and a uniform wall temperature conditions are applied along all blade surfaces including the blade tip. With the above conditions, an inlet Mach number of 0.174 is achieved. The working fluid is air whose Prandtl number is 0.7 .

A two-equation high Reynolds number turbulence model ( $k-\varepsilon$ with standard wall functions) is employed to model the turbulence. In all the simulations, the $Y^{+}$values of the first grid point away from the wall are maintained within 20-50. The standard wall functions have been found to be a good choice for simulating higher Reynolds number flow with a reasonable grid size and the results with wall functions show good prediction with experiments (Yang et al. [13]). All the cases presented here are converged to residual levels of order of $10^{-4}$, while the residual level for the temperature field was $10^{-7}$.

Grid independence is carried out by comparing solutions of a flat tip blade using three different grids having 549, 556, $803,775,932$, and 282 cells. For all cases, the grid is clustered near the tip and blade surfaces. Though the grid density is increased in the whole domain, the tip regions are refined the most, with $40 \%$ more grid points in the tip region for the intermediate grid and nearly double the number of grid points in the tip region for the fine grid. The numbers of cells in the spanwise direction within the tip gap region are 8,11 , and 16 for the coarse, intermediate, and fine grids, respectively. The grids in the other two-directions in the tip region are also refined for the grid independence study. Figure 3 shows the variation of the pressure ratio $\left(P_{t, \text { in }} / P\right)$ on the blade surface at $90 \%$ of the blade span for the three different grids. There is no significant difference in the pressure ratio for the three grid sizes. The local heat transfer coefficient for the three grids at the blade tip is presented in Figure 4 . There are no significant differences among the three simulations with the three different grids. The averaged values of the tip heat transfer coefficient for the three grids are $1381.99,1434.79$, and $1435.09 \mathrm{~W} / \mathrm{m}^{2}-\mathrm{K}$, respectively, and therefore the difference between the finest grid and the intermediate grid is $0.02 \%$, while the coarse grid value is $3.7 \%$ off the finest grid value. Therefore, calculations with the intermediate grid (803,775 cells) appear to be grid independent. All the simulations in this study are carried out using a grid with at least 803,775 cells. For the squealer tip and the winglet tip considered in the present study, additional grid

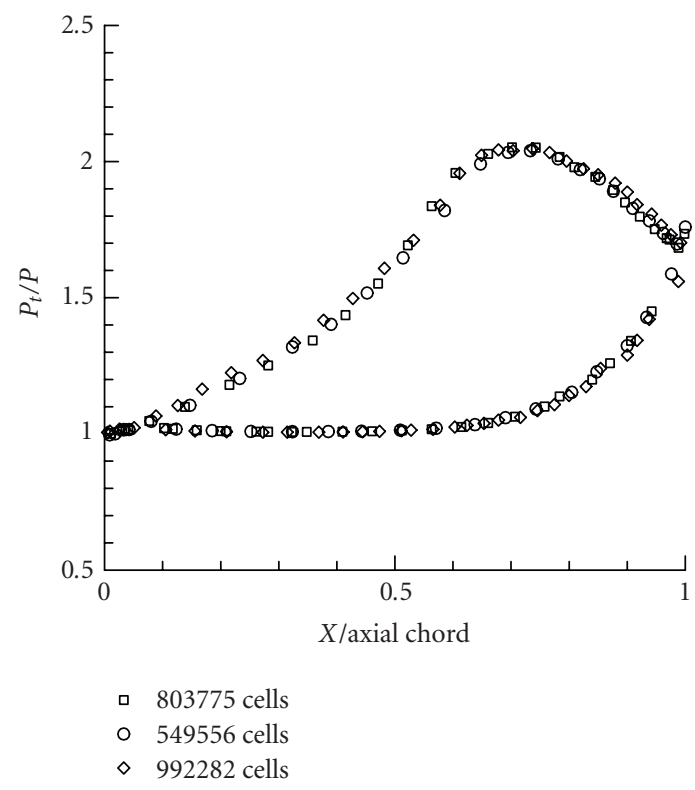

Figure 3: Distribution of pressure ratio $\left(P_{t} / P\right)$ at $90 \%$ of the blade span for 549556, 803775, and 992282 grids.

points, proportional to the geometrical modifications, were added.

\section{VALIDATION}

In an earlier study of a GE- $\mathrm{E}^{3}$ blade, with flat and squealer tips $[13,14]$, the present calculation procedure and turbulence model were validated against measurements, and shown to provide blade tip heat transfer predictions that agree with data to within 10-15\%. All the correct qualitative trends were predicted including the location and size of low and high heat transfer coefficient regions. It is therefore expected that the results of the present numerical study can be used to evaluate trends and the effects of the winglet on the tip heat transfer and leakage flow.

To provide additional validation, with the same blade as used in the present paper, the present code is validated against the experimental results of Jin and Goldstein [23], who performed pressure measurements and mass transfer measurements for the same high pressure turbine blade considered here, although with different scale up and flow conditions. The exit Reynolds number and the tip clearance gap are $5.8 \times 10^{5}$ and $0.86 \%$ respectively for Jin and Goldstein [23]. Computations are carried out using $1.6 \times 10^{6}$ mesh points at above Reynolds numbers. The higher number of grid points used for the validation case is due to the higher pitch $(13.8 \mathrm{~cm})$ and span used in the experiments $(45.7 \mathrm{~cm})$ than for the configuration of the present study. Figure 5 reveals the comparison of the blade surface coefficient of present computations with that of experiments. It is seen that there is good match between the predictions and data. Comparisons with the mass transfer data is not attempted due to questions 


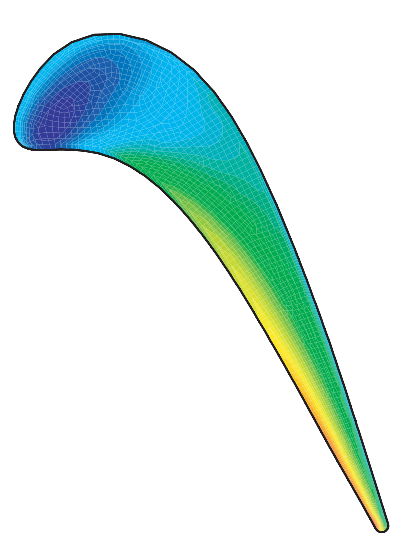

(a)

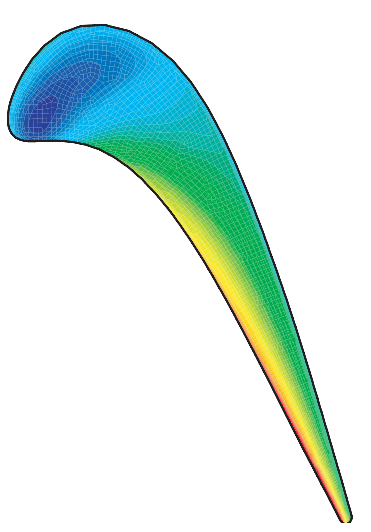

(b)

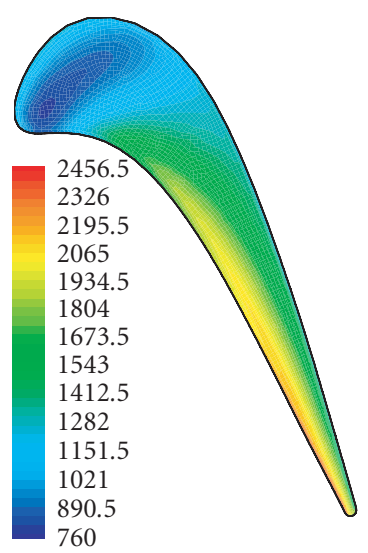

(c)

Figure 4: Contours of heat transfer coefficient $\left(h, \mathrm{~W} / \mathrm{m}^{2}-\mathrm{K}\right)$ at the blade tip for (a) 549556, (b) 803775, and (c) 992282 cells.

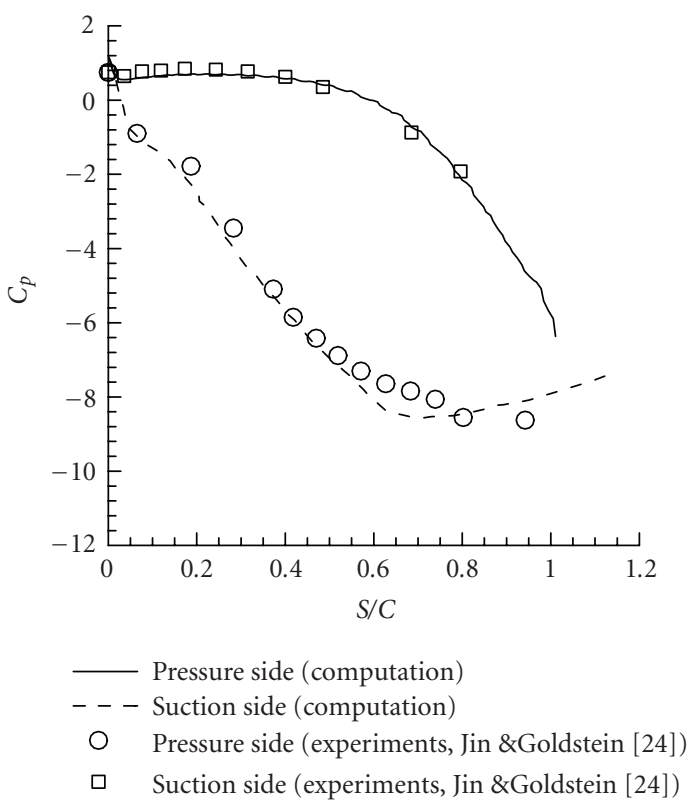

FIgURE 5: Comparison of pressure coefficient on the blade surface with experiments.

about the validity of the heat and mass transfer analogy under such conditions.

\section{RESULTS AND DISCUSSIONS}

As noted earlier, the effect of a pressure-side winglet is explored on three basic geometries: the flat tip, the full-squealer tip, and the suction-squealer tip. Results for these three geometries are presented in the sections below.

\subsection{Flat tip}

Figures 6(a) and 6(b) show the pressure ratio $\left(P_{t, \text { in }} / P\right)$ contours at the blade tip for the flat tip baseline and desensitized cases respectively. A higher value of the pressure ratio corresponds to a lower static pressure (higher velocity) and vice versa. In both the baseline and the winglet-tip cases, the pressure ratio distribution clearly demonstrates the tip leakage flow pattern, that is, the flow is from the lower value of $P_{t, \text { in }} / P$ on the pressure side towards the higher value of $P_{t, \text { in }} / P$ on the suction side. The pressure ratio distribution on the pressure and suction surfaces over most of the blade span is largely unaffected by the winglet, and is therefore not shown here. Comparison of Figures 6(a) and 6(b) shows a noticeable difference in the magnitude of the $P_{t, \text { in }} / P$ distribution on the blade tip. This, in turn, implies a difference in the net leakage flow through the tip gap. The key difference between the two cases occur in the region between $30 \%$ and $70 \%$ of the blade chord, where the leakage flow is the strongest, with the winglet tip showing lower pressure ratios. For example, at the mid-chord of the blade, the pressure ratio for the winglet tip midway between the pressure and suction edges is more than $25 \%$ lower. The lower $P_{t}$, in $/ P$ for the desensitized case signifies a lower leakage flow through the tip gap. This is likely to lead to lower heat transfer coefficients for the winglet tip.

The corresponding distribution of local heat transfer coefficient on the flat tip is shown in Figures $7(a)$ and 7(b). The heat transfer distribution demonstrates that the highest heat transfer coefficients (nearly $2500 \mathrm{~W} / \mathrm{m}^{2}-\mathrm{K}$ ) occur near the pressure side beyond the mid chord of the blade. The high heat transfer coefficients correspond to the regions where the pressure difference (see Figure 6) and the leakage velocity (see Figure 8) across the blade are the largest. The leading edge of the tip for both cases shows the lowest heat transfer coefficient since this region is associated with relatively lower velocities (see Figure 8). The heat transfer distribution for the desensitized case (Figure 7(b)) clearly reveals lower heat transfer than the baseline case (Figure $7(\mathrm{a})$ ). The average heat transfer coefficients on the tip surface for the baseline and desensitized tips are 1434.79 and 1336.13 $\mathrm{W} / \mathrm{m}^{2}-\mathrm{K}$, respectively, reflecting nearly a $7 \%$ difference between the cases. However, locally the reduction in the heat transfer coefficient can be as significant as 30\%. Thus, clearly 


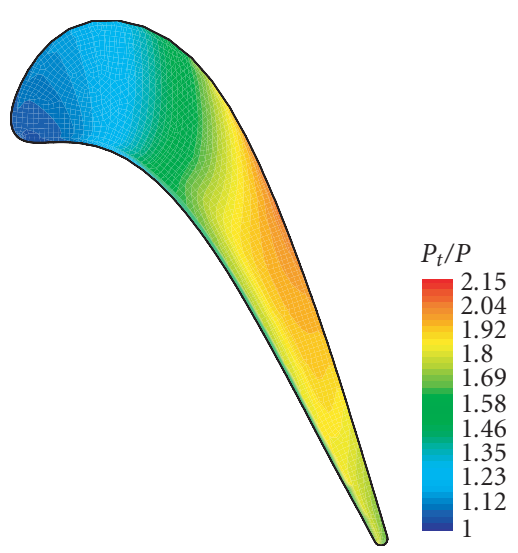

(a)

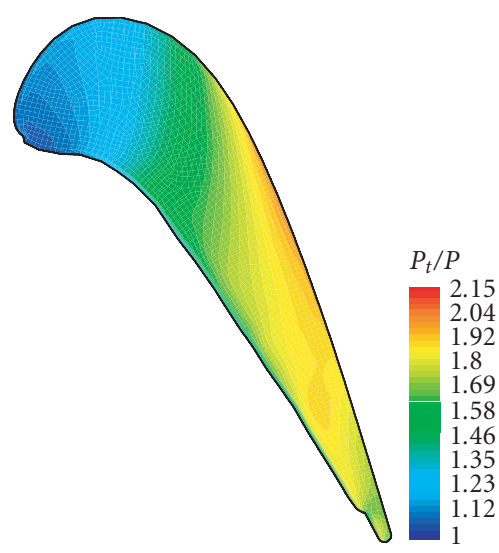

(b)

FIGURE 6: Contours of pressure ratio on the blade tip, (a) baseline flat tip and (b) desensitized flat tip.

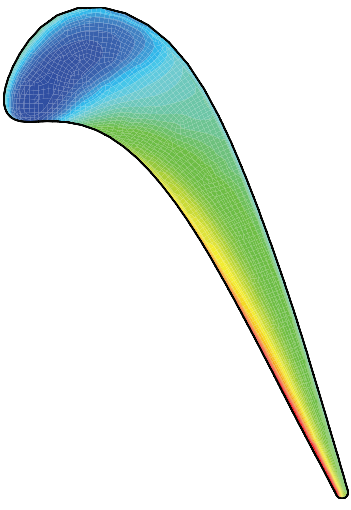

(a)

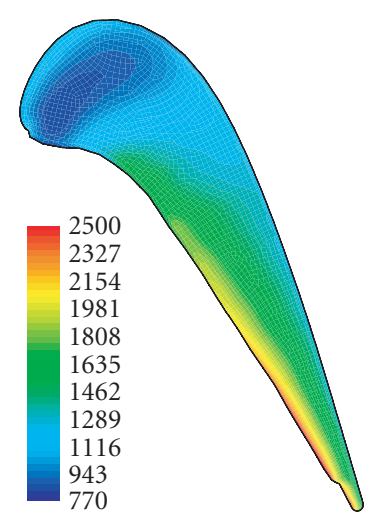

(b)

FIGURE 7: Contours of heat transfer coefficient $\left(\mathrm{W} / \mathrm{m}^{2}-\mathrm{K}\right)$ on blade tip, (a) baseline flat tip and (b) desensitized flat tip.

from a heat transfer perspective, the winglet provides a distinct reduction in the heat transfer coefficient. This reduction in heat transfer combined with the reductions in the pressure ratio (or leakage flow rate) observed earlier in Figure 6 indicates that the winglet is a suitable desensitization strategy for flat tips.

The computed streamlines superimposed on the in-plane velocity magnitude contours at the mid-height of the tip gap are presented in Figure 8 for both the cases. It can be seen that the velocity distribution in the gap is expectedly similar to the pressure ratio distribution on the blade tip region (see Figure 6). The maximum velocity in both cases are almost equal (baseline case shows relatively higher velocity), and there is little difference in the tip leakage flow pattern in the gap region for the two cases. The primary difference that can be seen in the two plots are relatively subtle: for the winglet tip, slightly lower velocities are seen close to the pressure side near $30 \%$ of axial chord, and a smaller region of the high-velocity leakage flow on the suction side is observed.
The distribution of the secondary flow vectors superimposed on the streamwise vorticity contours for the two cases is presented in Figure 9 on a cross-sectional plane at $40 \%$ axial chord. In Figure 9, distances in the $Y$ and $Z$ direction are normalized with the pitch length and the blade span, respectively. The streamwise vorticity is nondimensionalized using the blade span as the length scale and inlet velocity as the velocity scale, according to the following equation:

$$
\omega_{x, n}=\omega_{x} \frac{S}{U_{\text {in }}} .
$$

In Figure 9, the flow within the tip gap resembles that of a channel flow. Once the flow leaves the gap it rolls up into a leakage vortex on the suction side. Comparison of Figures 9(a) and 9(b) clearly illustrates that the leakage vortex is stronger and larger in size for the baseline flat-tip case. The magnitude of velocity vectors is greater for the baseline case. To get a quantitative estimate of the relative magnitude of the leakage vortex, the streamwise vorticity at a circumferential pitch location of $Y=0.7$ is plotted as a function of the blade 


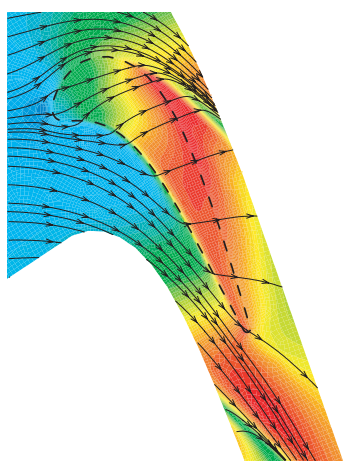

(a)

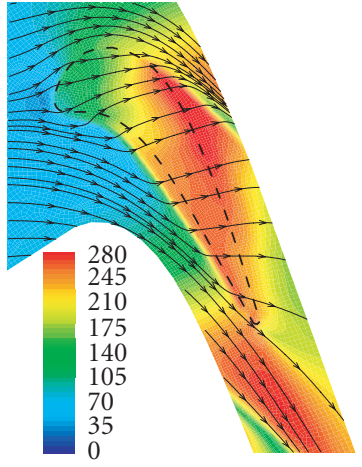

(b)

FIGURE 8: Streamlines superimposed on the in-plane velocity magnitude (m/s) contours at the mid-height of the tip gap (a) baseline flat tip and (b) desensitized flat tip.
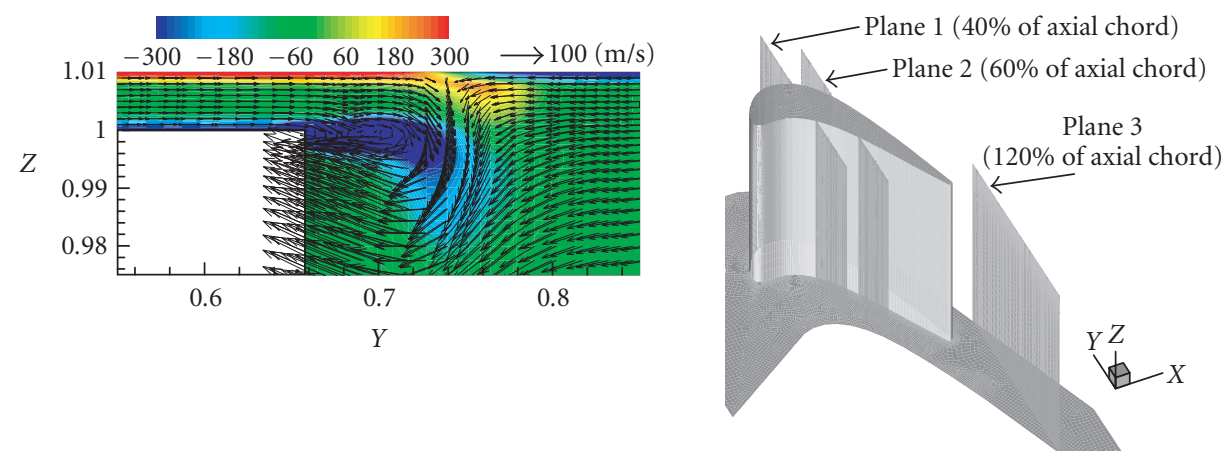

(a)
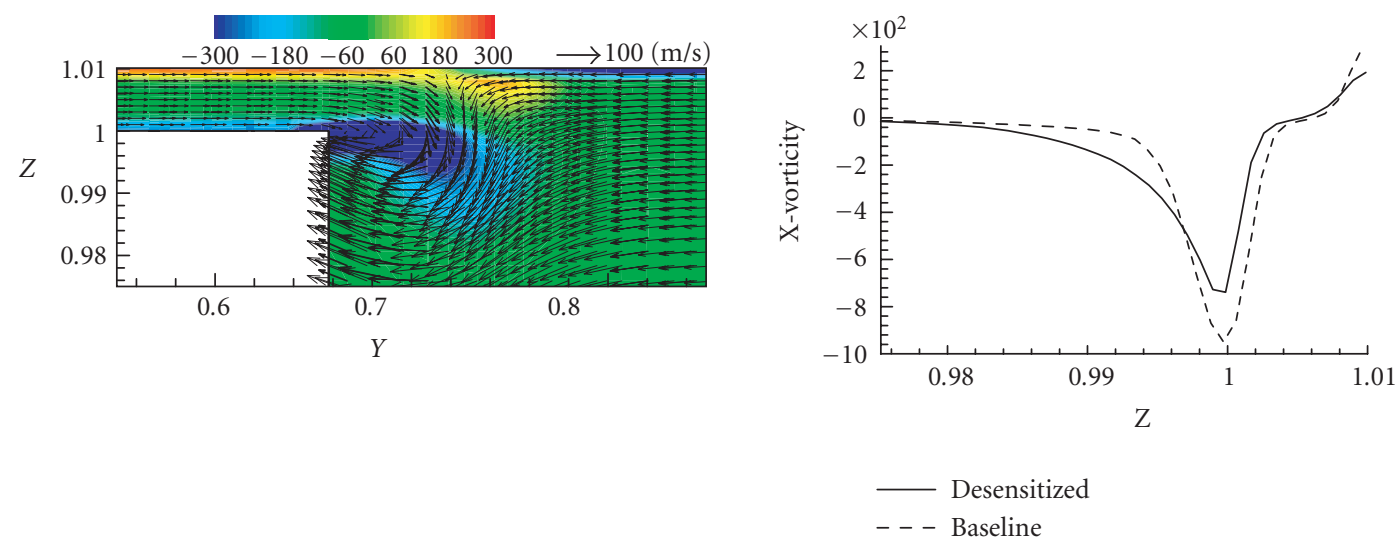

(b)

(c)

Figure 9: Tip leakage secondary vortices for (a) baseline flat tip, (b) desensitized flat tip, and (c) the relative magnitude of vorticity along the blade span for a constant $y=0.7$ at a streamwise location of $40 \%$ from the leading edge of the blade.

span and is shown in Figure 9(c). The leakage vortex for the desensitized case has a peak vorticity that is nearly $30 \%$ lower than the flat-tip baseline case. At $Y=0.75$, representing roughly the outer edge of the leakage vortex, the spanwise dimension of the vortex with the winglet is nearly $75 \%$ that of the baseline case. The smaller size and the reduced vorticity strength with the winglet both imply a net reduction in aerodynamic losses with the winglet.

The pressure ratio $\left(P_{t, \text { in }} / P\right)$ and $\left(P_{t, \text { in }} / P_{t, \text { local }}\right)$ contours at a streamwise location corresponding to $120 \%$ of the axial 

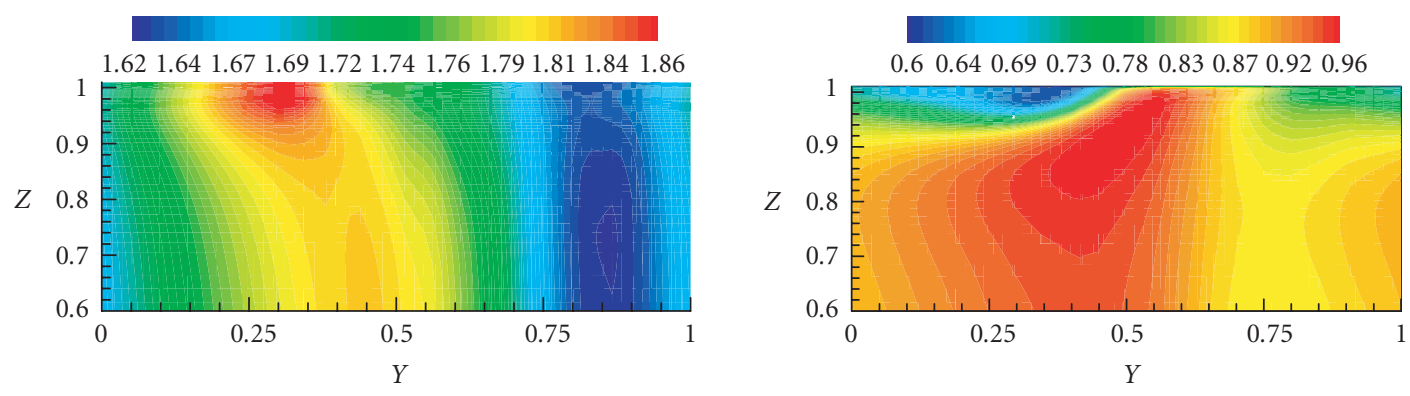

(a)
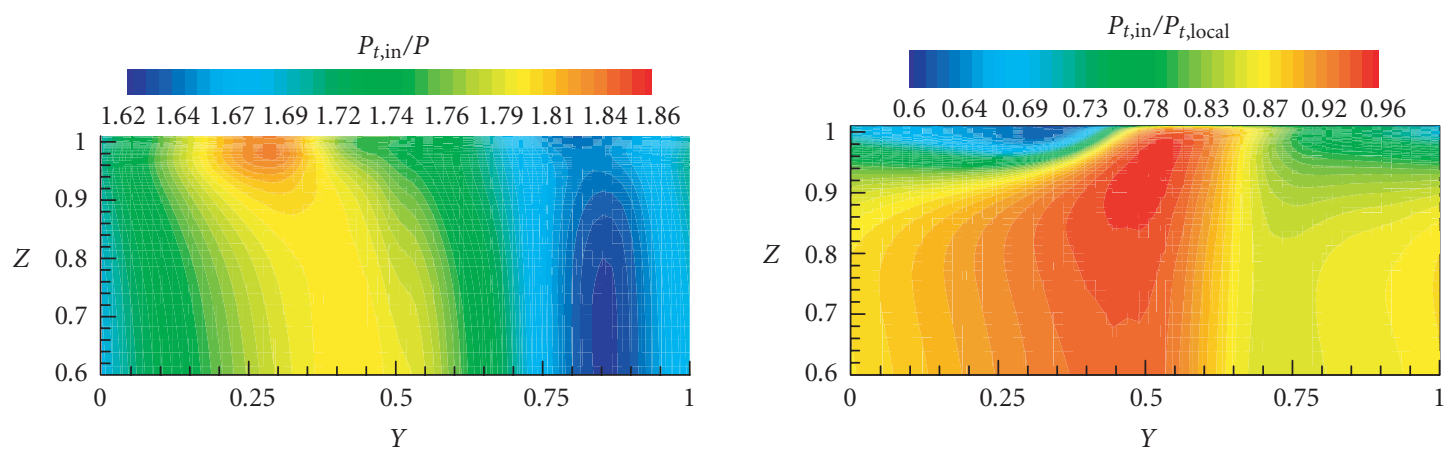

(b)

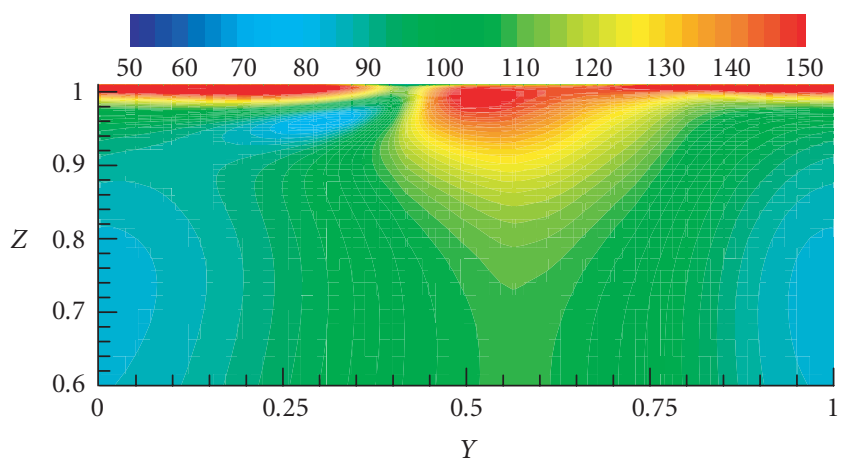

(c)

Figure 10: Contours of the pressure ratio $\left(P_{t, \text { in }} / P\right)$ and $\left(P_{t, \text { in }} / P_{t, \text { local }}\right)$ at a streamwise location of $120 \%$ from the leading edge of the blade, (a) baseline flat tip, (b) desensitized flat tip, and (c) contours of streamwise velocity $(\mathrm{m} / \mathrm{s})$ for baseline flat tip.

chord are presented in Figure 10. The high-pressure ratio region corresponds to the high-velocity passage flow between two adjacent blades. These pressure ratios are seen to increase toward the tip region where the effective area for the passage flow is lower due to the area occupied by the leakage vortex. Downstream of the blade, the leakage vortex pushes the passage flow near the tip towards the suction side of the adjacent blade. Contour plots of the streamwise velocity (velocity in the $X$-direction) in Figure 10(c) clearly confirm this observation where the leakage flow at the top pushes the flow towards the suction side. While the distribution of the pressure coefficient for both the baseline (Figure 10(a)) and the desensitized cases (Figure 10(b)) is similar, their relative magnitudes are different. The desensitized case is seen to show lower peak pressure ratios because of the lower strength of leakage vortex. To quantitatively compare the aerodynamic pressure losses for the two cases, a pressure loss coefficient is calculated as

$$
C_{p, \text { loss }}=\frac{P_{t, \text { in }}-P_{t, \text { local }}}{P_{t, \text { in }}}
$$

where $P_{t, \text { local }}$ and $P_{t \text {, inlet }}$ are the local and inlet total pressures, respectively. Both area- as well mass-weighted averages are computed. There is no observed significant difference. Therefore, area-weighted averages are reported. The computed average pressure loss coefficients for the baseline and desensitized cases are 0.1143 and 0.1009 . 


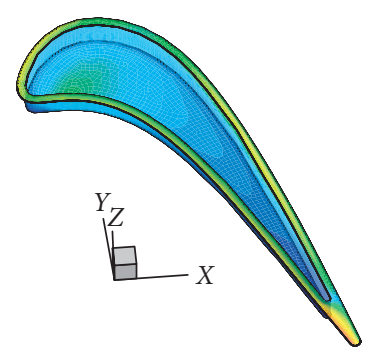

(a)

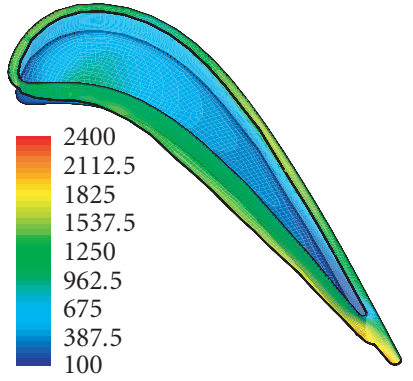

(b)

Figure 11: Contours of heat transfer coefficient on blade tip, (a) baseline squealer tip and (b) desensitized squealer tip.

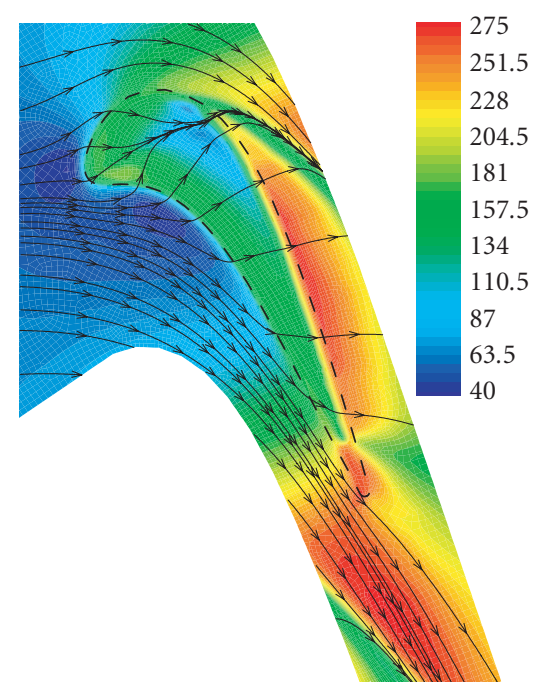

FIGURE 12: Streamlines superimposed on the in-plane velocity magnitude $(\mathrm{m} / \mathrm{s})$ contours at the mid-height of the tip gap for baseline squealer tip.

In summary, the pressure-side winglet leads to considerable reduction in the leakage vortex strength, and modest reductions in the tip heat transfer. Subject to manufacturing constraints, adding a winglet on a flat-tip blade appears to be a promising concept.

\subsection{Squealer tip}

In this section, the effectiveness of the winglet for a fullsquealer tip blade is examined. The spatial distribution of the heat transfer coefficient on the blade tip for the baseline and desensitized squealer tip is shown in Figure 11. It is evident that the squealer tip has considerably lower heat transfer, with the area-averaged value being nearly half that for a flat tip. This is a consequence of the flow recirculation induced by the squealer (Figures 12 and 13), due to which, the flow velocity immediately above the squealer-cavity floor is reduced. The leakage flow patterns over the squealer-cavity are distinctly different from those over a flat-tip (compare Figures 12 and 8 ), and flow entering the gap near the lead-

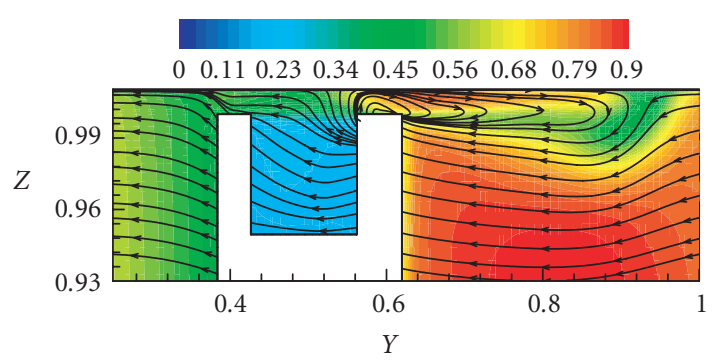

(a)

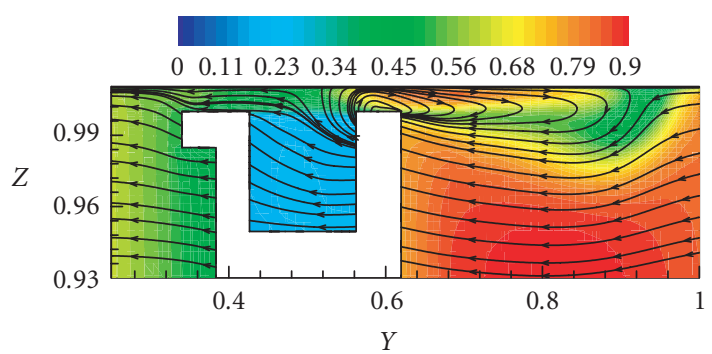

(b)

FIGURE 13: Secondary flow distribution superimposed on the Mach number contour at a streamwise location of $60 \%$ from leading wall of the blade, (a) baseline squealer tip and (b) desensitized squealer tip.

ing edge of the blade impinges on the floor of the squealer cavity. As a consequence, the tip heat transfer coefficient is highest in the vicinity of the leading edge. The flat tip, on the other hand, has a "sweet-spot" or the lowest heat transfer coefficient in the vicinity of the leading edge. The highest heat transfer coefficient is observed on top of the squealer rim, and in the vicinity of the trailing edge (with no squealer) since highly accelerated flow passes over these surfaces.

In comparing the heat transfer coefficients for both the baseline and the desensitized cases, the distributions and the magnitudes look almost similar (Figures 11(a) and 11(b)). The area-averaged heat transfer coefficients for both the baseline and the desensitized cases are close to $660 \mathrm{~W} / \mathrm{m}^{2}-\mathrm{K}$. 
Clearly, adding a winglet, for the specific squealer tip depth considered in the present study, did not impact the heat transfer coefficient distribution.

Figure 12 shows in-plane pathlines superimposed on the in-plane velocity magnitude contours at the mid-height of the tip gap. As mentioned earlier, the flow in the squealer-tip region is distinctly different than the corresponding flow over a flat tip, and the cavity flow is strongly three dimensional with the streamlines from the leading edge directed toward the trailing edge, bouncing off the pressure-side squealer, and eventually exiting on the suction side. The velocity magnitude contours indicate that over most of the squealer-tip region, the velocities are considerably lower than those over a flat tip (compare Figure 12 with Figure 8(a)), but the leakage flow accelerates as it exits the suction-side squealer rim reaching velocities on the suction side comparable (although lower in magnitude) to those for a flat-tip blade. However, as for the flat tip case, no intrinsic changes in the flow pattern occur with the addition of a pressure-side winglet, and therefore these plots are not presented here.

Figure 13 plots the secondary flow streamlines superimposed on the Mach number contours at 60\% axial chord for the two cases. Though the overall flow pattern is similar in the two cases, small differences can be seen in the streamline pattern particularly in the vicinity of the suction-side squealer. However, these differences are small, and as seen earlier, do not produce any difference in the surface heat transfer.

The leakage flow vector plot superimposed on the streamwise vorticity contours at $40 \%$ chord length is shown in Figure 14. At the $40 \%$ chord location, the recirculation is marginally stronger for the baseline case. No significant difference in size of the leakage vortex is found between the baseline and desensitized cases shown in Figure 14. However, there is a small difference in the magnitude, and in the vortex core, the leakage vortex with the winglet is weaker (Figure 14(c)).

The comparison of the pressure ratio at $120 \%$ of the chord length reveals that there is no remarkable quantitative and qualitative difference in the pressure ratio for the two cases and therefore is not shown here. The pressure loss coefficients for the baseline and desensitized cases have been computed to be 0.1059 and 0.1007 . The lower value of pressure loss for the desensitized case can be attributed to the presence of the winglet. Clearly the effect of the winglet in reducing aerodynamic loss is considerably less for the full squealer case.

\subsection{Suction-side squealer}

The suction-side squealer is a modified version of the full squealer tip where the squealer is located only on the suction side of the blade. The flow structure in this configuration is quite different from the full squealer as there is no cavity in the tip region. As for the full squealer, no significant difference is observed between the baseline and desensitized cases. Therefore, most of the discussion in this section is based either on the baseline or the desensitized case alone.

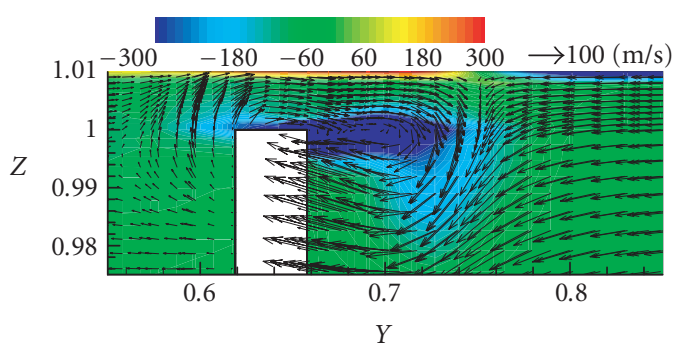

(a)

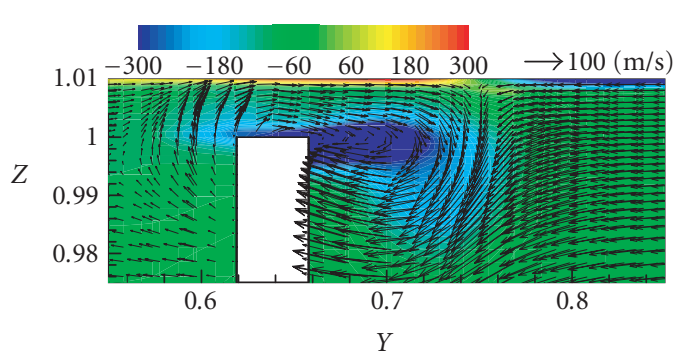

(b)

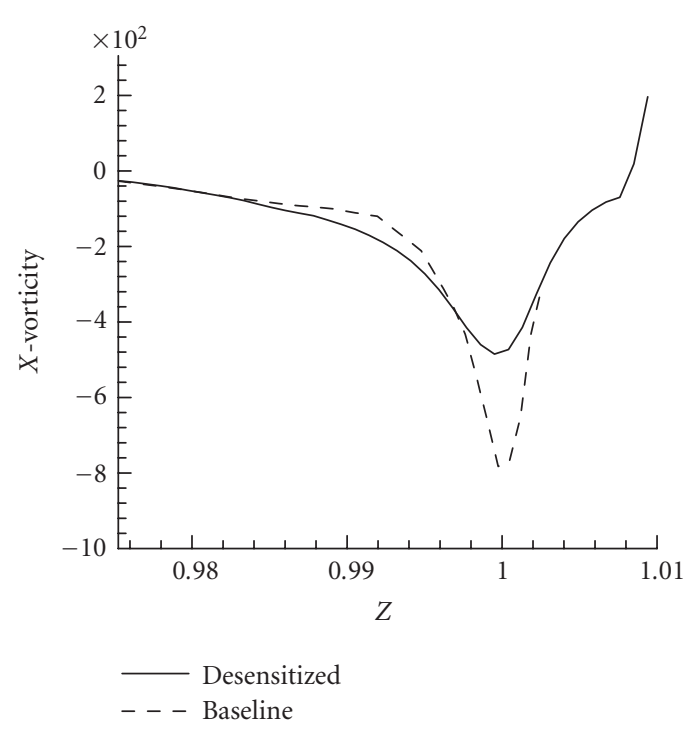

(c)

FIGURE 14: Tip leakage secondary vortices for (a) baseline squealer tip, (b) desensitized squealer tip, and (c) the relative magnitude of vortices along the blade span for a constant $y=0.7$ at a streamwise location of $40 \%$ from the leading edge of the blade.

Figure 15(a) depicts the pressure ratio contours on the tip surface of the blade for the desensitized case. The pressure coefficient is found to be the maximum on the squealer tip and near the trailing edge of the blade. The lowest pressure ratios are observed near the suction side of the blade just upstream of the suction-side rim. The distribution of the heat transfer coefficient is presented in Figure 15(b). The blade tip shows lower heat transfer coefficient relative to the flat tip, and shows the lowest value near the leading edge of the blade. The surface averaged heat transfer coefficient for the baseline and the desensitized cases are found to be 823.62 and 812.11 


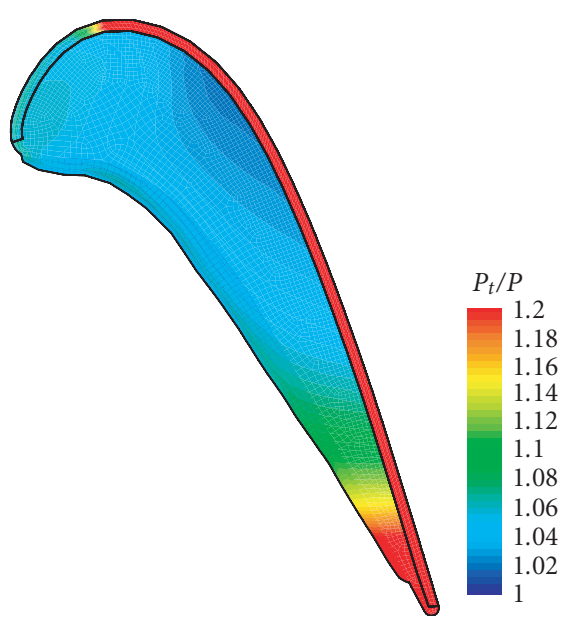

(a)

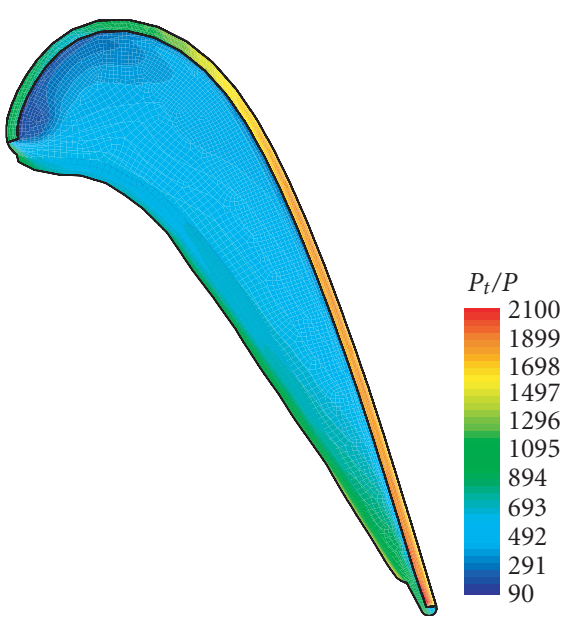

(b)

Figure 15: (a) Pressure ratio and (b) heat transfer contours on the desensitized suction-side squealer tip.

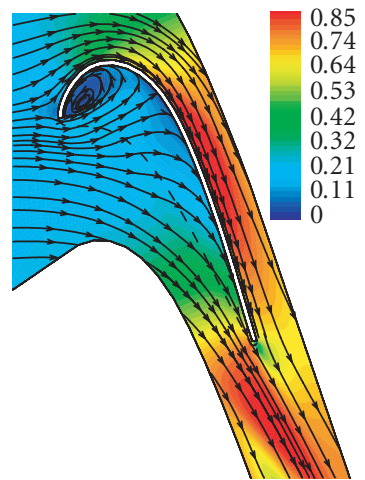

(a)

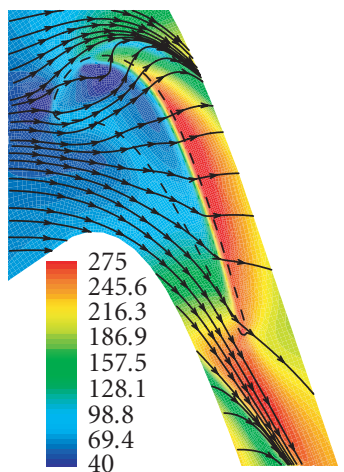

(b)

FIGURE 16: Streamtraces superimposed on Mach number contours at (a) the mid-height of the rim and (b) the mid-height of the tip gap for the baseline suction-side squealer.

$\mathrm{W} / \mathrm{m}^{2}-\mathrm{K}$. Therefore, there is no significant change in heat transfer obtained with the desensitization procedure. Note that the average heat transfer coefficients with the suctionside squealer are nearly $30 \%$ greater than the full squealer and nearly $30 \%$ lower than the flat tip. It is to be noted that the pressure distribution at the shroud shows similar variation of pressure. This is because of the fact that the small tip gap does not show significant variation of pressure even in a strong three-dimensional flow within the tip gap.

Figure 16(a) represents the streamtraces superimposed on the Mach number contours at the mid section of the rim (note that the plane is not in tip gap), while Figure 16(b) shows the corresponding plot at the mid-height within the tip gap. The overall pattern of the leakage flow is similar to the earlier two baseline cases with the exception that the leakage flow starts close to the leading edge of the blade. However, the contours of velocity magnitude shows that the distribution is more similar to the squealer tip with low velocities over the tip region, and a separated flow over a significant portion of the tip.

The streamtraces of the secondary flow at an axial location of $40 \%$ from the leading edge of the blade is plotted in Figure 17 for both the baseline and desensitized cases. The streamtraces are superimposed on Mach number contours. There is clear evidence of the recirculation near pressure side of the blade tip. Due to the reattachment of the recirculating flow, higher heat transfer coefficients are seen in the vicinity of the recirculating eddy (see Figure 15). The heat transfer on the tip of the squealer rim is the highest due to the highly accelerated flow through this region as seen in Figure 17. The overall distribution of secondary flow is similar for both the baseline and winglet cases. However, there are differences in the magnitude with the Mach number near the blade tip being lower for the baseline case than the desensitized case. These differences are not significant to produce appreciable differences in the tip heat transfer coefficient. 


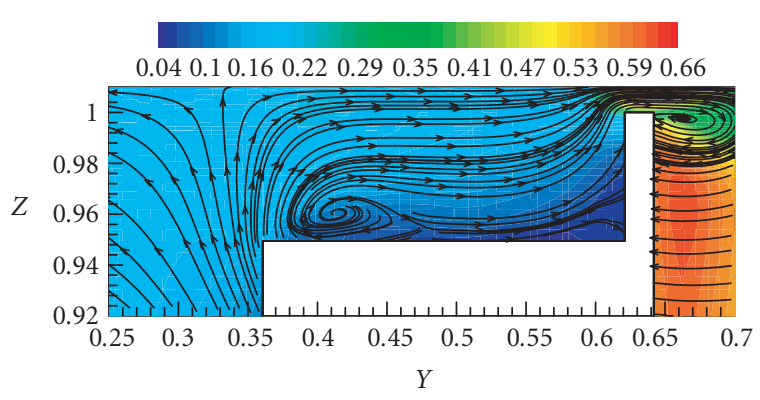

(a)

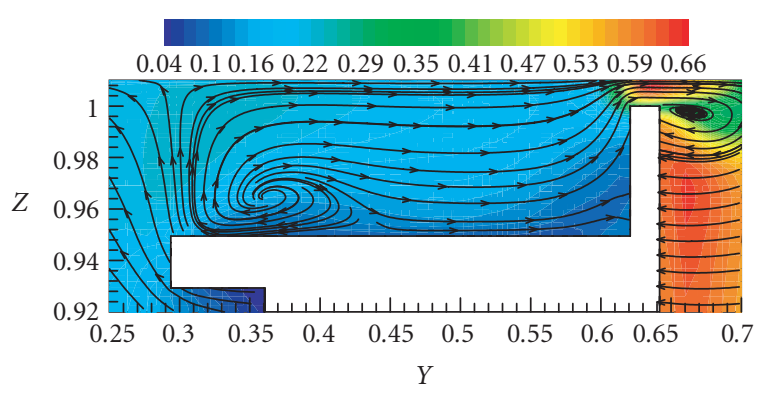

(b)

FIgURE 17: Secondary flow distribution superimposed on the Mach number contour at a streamwise location of $40 \%$ from leading wall of the blade, (a) baseline suction-side squealer tip and (b) desensitized suction-side squealer tip.

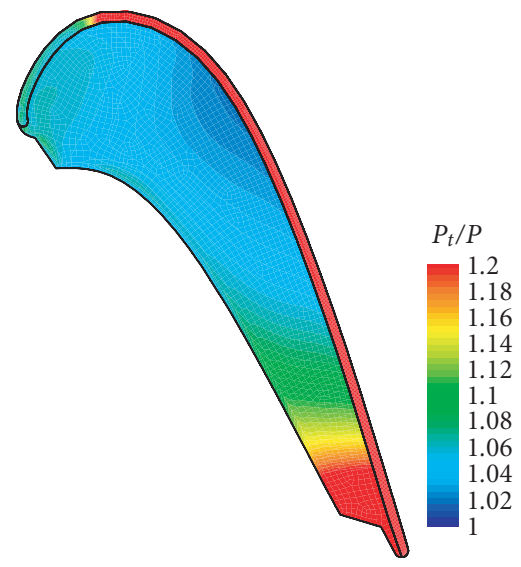

(a)

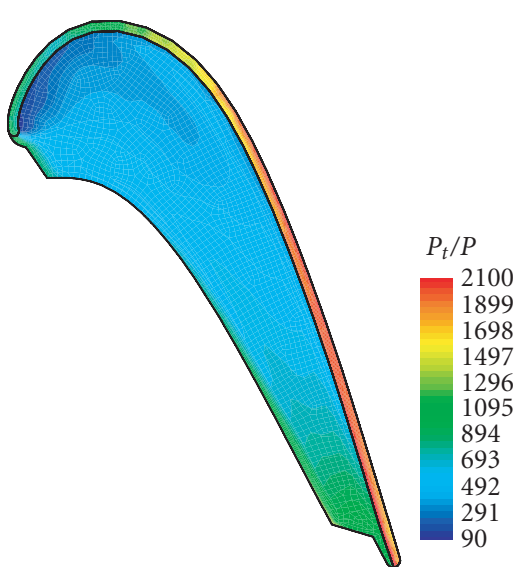

(b)

FIGURE 18: (a) Pressure ratio and (b) heat transfer contours on the desensitized suction-side squealer tip having a constant width.

Similar to the flat tip, the contours of pressure coefficient were drawn for the two cases and no noticeable difference was observed at an axial location 120\% of the chord length (not shown). The pressure loss coefficient is calculated at this location with respect to the inlet total pressure for the baseline and the desensitized cases and is found to be 0.1029 and 0.1003 , respectively. Thus, as for the full squealer, the winglet produces a rather small reduction in the aerodynamic loss.

\subsection{Suction-side squealer having winglet of constant width}

In this section, the computational results of suction-side squealer with constant width winglet are discussed. Unlike the other cases, the width ( $w$ ) of the winglet along the blade periphery is kept constant. The width $(\mathrm{w})$ and the thickness (s) of the winglet are kept at $5 \%$ of the blade span.

The pressure ratio on the blade tip and squealer tip regions is shown in Figure 18(a). The distribution on the blade tip region is observed to be almost constant having a low value while the distribution on the squealer tip shows wide variation of pressure ratio. The higher value of pressure ratio corresponds to the low velocity and vice versa. Therefore, the distribution shows that the fluid velocity is high near the leading edge of the blade but the fluid velocity drops with increasing distance. The surface heat transfer coefficient on the blade and squealer tip regions is presented in Figure 18(b). The heat transfer is more near the trailing edge of the blade tip, while the enhancement is highest at the squealer tip. Comparison of Figures 15(b) and 18(b) shows that increasing the thickness and the making the width constant decreases the heat transfer near the leading section of the blade tip while it increases the heat transfer on the squealer tip. Thus there may be possibility for the squealer rim to be burnt out faster because of the higher heat transfer in a thin section of the rim. The average heat transfer coefficient is 778.11 $\mathrm{W} / \mathrm{m}^{2}-\mathrm{K}$, which is $5.5 \%$ less than the baseline suction-side squealer. However, the similar winglet with variable width and thinner thickness resulted in higher heat transfer coefficient $\left(812.11 \mathrm{~W} / \mathrm{m}^{2}-\mathrm{K}\right)$.

The contours of Mach number and secondary stream traces at $40 \%$ axial chord location are presented in Figure 19(a). Comparison of the present result with that of variable width in Figure 17(b) shows that the overall pattern of the secondary flow with the Mach number distribution remains the same although there is an increase in maximum 


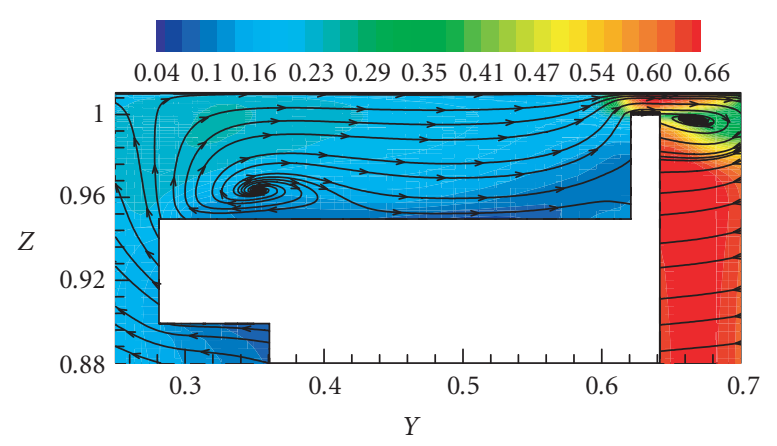

(a)

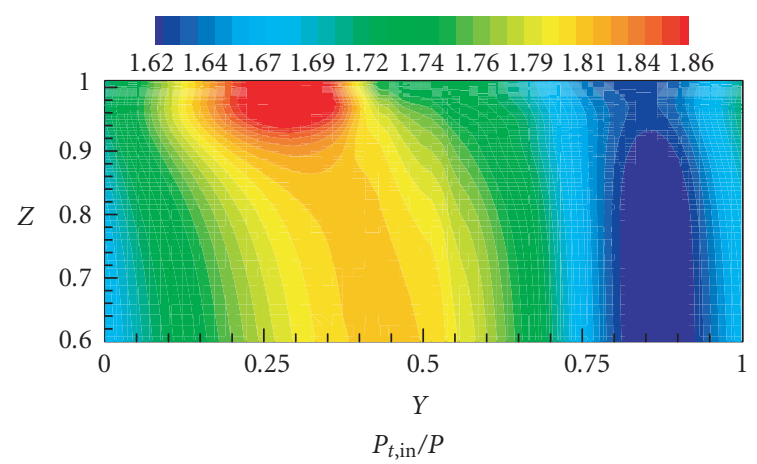

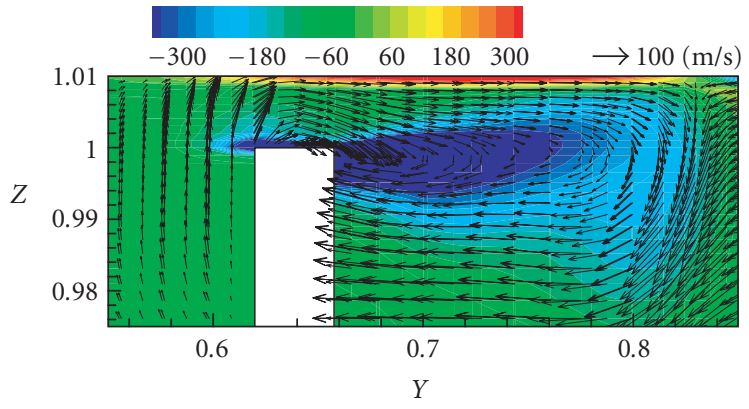

(b)

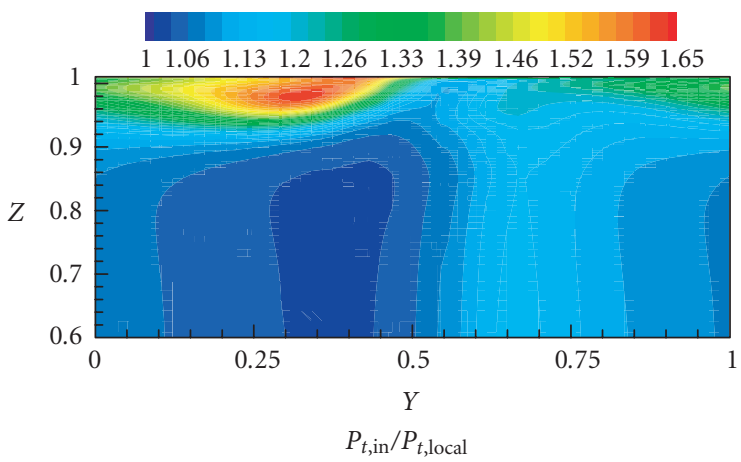

(c)

Figure 19: (a) Secondary flow distribution superimposed on the Mach number contour at a streamwise location of $40 \%$ from leading wall of the blade, (b) tip leakage secondary vortices at a streamwise location of $60 \%$ from the leading edge of the blade, and (c) contours of the pressure ratio $\left(P_{t, \text { in }} / P\right)$ and $P_{t, \text { in }} / P_{t, \text { local }}$ at a streamwise location of $120 \%$ from the leading edge of the blade.

TABLE 1: Comparison of heat transfer coefficient and pressure loss coefficient for various cases.

\begin{tabular}{l|cc}
\hline Cases & $\begin{array}{c}\text { Surface heat transfer } \\
\text { coefficient, } h, \mathrm{~W} / \mathrm{m}^{2}-\mathrm{K}\end{array}$ & $\begin{array}{c}\text { Pressure loss coefficient } \\
\text { (at 120\% of the axial chord) }\end{array}$ \\
\hline Baseline flat tip & 1434.79 & 0.1009 \\
Desensitized flat tip & 1336.13 & 0.1143 \\
Baseline squealer tip & 660 & 0.1059 \\
Desensitized squealer tip & 660 & 0.1007 \\
Baseline suction-side squealer & 823.62 & 0.1029 \\
Desensitized suction-side squealer (variable width and thickness $=2 \%)$ & 812.11 & 0.1003 \\
Desensitized suction-side squealer (constant width and thicknes $=5 \%)$ & 778.11 & 0.0760 \\
\hline
\end{tabular}

Mach number value in the suction side of the blade (region between $0.64 \leq y \leq 0.7)$ for constant width winglet. The tip leakage vortex and the vortex at the blade tip at this location for both cases (constant width and variable width) look identical. Figure 19(b) shows the secondary flow structure and the contours of the streamwise vorticity. Compared to the other cases the vortical structure is elongated in the transverse direction. However, the relative strength of the secondary flow is comparable to the variable width squealer.

The contours of pressure ratio, $P_{t, \text { in }} / P$ at a location $120 \%$ of the axial chord from the leading edge of the blade are depicted in Figure 19(c). Although the variation of the pressure ratio is similar to the other cases, the maximum value is more for this case than any other cases discussed earlier. A higher value of the pressure ratio corresponds to the lower value of local pressure and vice versa. The lower value of local pressure results in lower total pressure and thus leads to lower value of pressure loss coefficient. The calculated pressure loss coefficient at $120 \%$ chord length is found to be 0.0760 , which is lower than all other cases presented in the study and is $26 \%$ less than the baseline suction-side squealer.

Table 1 lists the surface heat transfer coefficient and pressure loss coefficient at $120 \%$ of the axial chord for the various cases simulated in the present study. Comparison of the 
various cases reveals that the squealer tip cases show the lowest heat transfer, while the flat ones give the highest. The gap within the squealer rim acts as pressure recovery device and decelerates the flow with the tip gap and gives rise to lower heat transfer compared to the flat tip. Additionally, the partial exposure of the tip surface to the leakage flow also reduces the heat transfer. The pressure loss coefficient has been found to be the least for the desensitized suction-side squealer having constant width winglet and the highest for desensitized flat tip. In most cases, the use of winglet reduces the pressure loss while it increases for flat tip. The maximum reduction is observed in suction-side squealer but the heat transfer reduction is about $5.52 \%$. Overall comparison shows that the use of winglet is beneficial for the suction-side squealer.

\section{CONCLUDING REMARKS}

Numerical calculations have been performed for a flat tip and a squealer tip turbine blade at a pressure ratio of 1.73 , and the role of a pressure-side winglet in reducing the leakage flow and the tip heat transfer is explored. The calculations are performed using a finite-difference RANS code and a twoequation model for turbulence. Three cases are studied: flat tip, two-sided squealer tip, and suction-sided squealer tip. In all cases, the winglet is located only on the pressure side, and is shaped in the axial chord direction so as to have the maximum thickness at the location corresponding to the maximum pressure gradient across the blade. The following observations are made in this study.

(1) For a flat tip, the pressure-side winglet leads to significant reductions (order of 30\%) in the local heat transfer coefficient on the blade tip. The average reduction in the area-averaged heat transfer coefficient is nearly $7 \%$. The $30 \%$ reduction in local heat transfer coefficient occur near the pressure side where hot-spots typically occur for flat-tip blades.

(2) With the winglet, there is a significant reduction in the strength of the leakage flow, and the vorticity associated with it. At 70\% span, and 60\% axial chord, the reduction in the tip leakage vorticity due to the winglet is nearly $25 \%$.

(3) For the two-sided squealer tip, with a squealer height that is $5 \%$ of the blade span, the winglet produces only marginal improvements. While the strength of the leakage vortex is reduced by the winglet, no reduction in the pressure loss coefficient or in the average tip heat transfer coefficient was obtained.

(4) For the suction-sided squealer tip, the pressure-side winglet again provides no significant improvements, with a $0.3 \%$ decrease in the overall pressure loss coefficient, and a $1.5 \%$ decrease in the average heat transfer coefficient.

(5) The suction-sided squealer tip having constant width and thicker winglet shows lower heat transfer (5.5\%) as well as pressure loss coefficient (26\%) than the baseline suction side squealer and is found to be better choice than others.

\section{NOMENCLATURE}

$\begin{array}{ll}C_{p, \text { loss }} & \text { Pressure loss coefficient } \\ C_{x} & \text { Axial chord length } \\ w & \text { Width of the winglet } \\ s & \text { Thickness of the winglet } \\ h & \text { Local convective heat transfer coefficient } \\ P & \text { Local static pressure } \\ P_{t} & \text { Total pressure } \\ P_{t, \text { in }} & \text { Total pressure at inlet } \\ P / S & \text { Pressure side of the blade } \\ S / S & \text { Suction side of the blade } \\ S & \text { Blade span } \\ T_{\infty} & \text { Mainstream temperature of the flow } \\ T u & \text { Turbulence intensity at the inlet } \\ u_{\tau} & \text { Friction Velocity } \\ U_{\text {in }} & \text { Inlet Velocity } \\ X & \text { Axial distance } \\ y_{p} & \text { Distance from the wall } \\ Y^{+} & \text {Dimensionless distance from the wall, } u_{\tau} y_{p} / \nu \\ \nu & \text { Kinematic viscocity. }\end{array}$

\section{ACKNOWLEDGMENTS}

This work was supported by a grant from the NSF-GOALI program with General Electric Global Research and General Electric Aircraft Engine Company as the industrial partners. Support from both NSF and the General Electric Company is gratefully acknowledged.

\section{REFERENCES}

[1] R. E. Mayle and D. E. Metzger, "Heat transfer at the tip of an unshrouded turbine blade," in Proceedings of the 7th International Heat Transfer Conference, pp. 87-92, Munich, Germany, September 1982.

[2] D. E. Metzger and K. Rued, "Influence of turbine clearance gap leakage on passage velocity and heat transfer near blade tips. Part I. Sink flow effects on blade pressure side," ASME Journal of Turbomachinery, vol. 111, no. 3, pp. 284-292, 1989.

[3] T. C. Booth, P. R. Dodge, and H. K. Hepworth, "Rotor-tip leakage part 1-basic methodology," ASME Journal of Engineering for Gas Turbines and Power, vol. 104, pp. 154-161, 1982.

[4] C. H. Sieverding, "Recent progress in the understanding of basic aspects of secondary flows in turbine blade passages," ASME Journal of Turbomachinery, vol. 114, pp. 248-257, 1985.

[5] J. P. Bindon, "Pressure distributions in the tip clearance region of an unshrouded axial turbine as affecting the problem of tip burnout," in Proceedings of International Gas Turbine Conference, Anaheim, Calif, USA, June 1987, 87-GT-230.

[6] J. Moore and J. S. Tilton, "Tip leakage flow in a linear turbine cascade," ASME Journal of Turbomachinery, vol. 110, no. 1, pp. 18-26, 1988.

[7] R. Bunker, "A review of turbine blade tip heat transfer," Annals of the New York Academy of Sciences, vol. 934, pp. 64-79, 2001.

[8] F. J. G. Heyes, H. P. Hodson, and G. M. Dailey, "The Effect of Blade Tip Geometry on the Tip Leakage Flow in Axial Turbine Cascade," ASME, 91-GT-135, 1991.

[9] T. T. Yang and T. E. Diller, "Heat Transfer and Flow for a Grooved Turbine Blade Tip in a Transonic Cascade," ASME 95-WA/HT-29, 1995. 
[10] A. A. Ameri, E. Steinthorsson, and L. D. Rigby, "Effect of Squealer Tip on Rotor Heat Transfer and Efficiency," ASME 99-GT-169, 1997.

[11] A. A. Ameri and R. Bunker, "Heat transfer and flow on the first-stage blade tip of a power generation gas turbine: part 2simulation results," ASME Journal of Turbomachinery, vol. 122, no. 2, pp. 272-277, 2000.

[12] R. Bunker, J. C. Bailey, and A. A. Ameri, "Heat Transfer and Flow on the First Stage Blade Tip of a Power Generation Gas Turbine: Part 1: Experimental Results," ASME 99-GT-169, 1999.

[13] H. Yang, S. Acharya, S. Ekkad, C. Prakash, and R. Bunker, "Flow and Heat Transfer Predictions for a Flat-Tip Turbine Blade," ASME GT-2002-30190, 2002.

[14] H. Yang, S. Acharya, S. Ekkad, C. Prakash, and R. Bunker, "Flow and Heat Transfer Predictions for a Squealer-Tip Turbine Blade," ASME 2002-GT-30193, 2002.

[15] G. M. Azad, J. C. Han, and R. Boyle, "Heat Transfer and Pressure Distribution on the Squealer Tip of a Gas Turbine Blade Tip," ASME 2000-GT-0194, 2000.

[16] N. W. Harvey and K. Ramsdan, "A Computational Study of a Novel Turbine Rotor Partial Shroud," ASME paper 2000-GT668, 2000.

[17] D. Dey and C. Camci, "Aerodynamic Tip Desensitization of an Axial Turbine Rotor Using Tip Platform Extensions," ASME Paper 2001-GT-0484, 2001.

[18] J. P. Bindon and G. Morphis, "Development of axial turbine leakage loss for two profiled tip geometries using linear cascade data," ASME Journal of Turbomachinery, vol. 114, no. 1, pp. 198-203, 1992.

[19] J. Tallman and B. Lakshminarayana, "Methods of Desensitizating Tip Clearance Effects in Turbines," ASME GT-2001-0486, 2001.

[20] G. T. Chen, W. N. Dawes, and H. P. Hodson, "A Numerical and Experimental Investigation of Turbine Tip Gap Flow,” AIAA Paper 93-2253, 1993.

[21] J. B. Staubach, O. P. Sharma, and G. M. Stetson, "Reduction of tip clearance losses through 3D air foil designs," in Proceedings of ASME/IGTI Conference, Singapore, 1996.

[22] M. Papa, R. J. Goldstein, and F. Gori, "Effects of tip geometry and tip clearance on the mass/heat transfer from a large-scale gas turbine blade," ASME Journal of Turbomachinery, vol. 125, no. 1, pp. 90-96, 2003.

[23] P. Jin and R. J. Goldstein, "Local mass/heat transfer on turbine blade near-tip surfaces," ASME Journal of Turbomachinery, vol. 125, no. 3, pp. 521-528, 2003. 

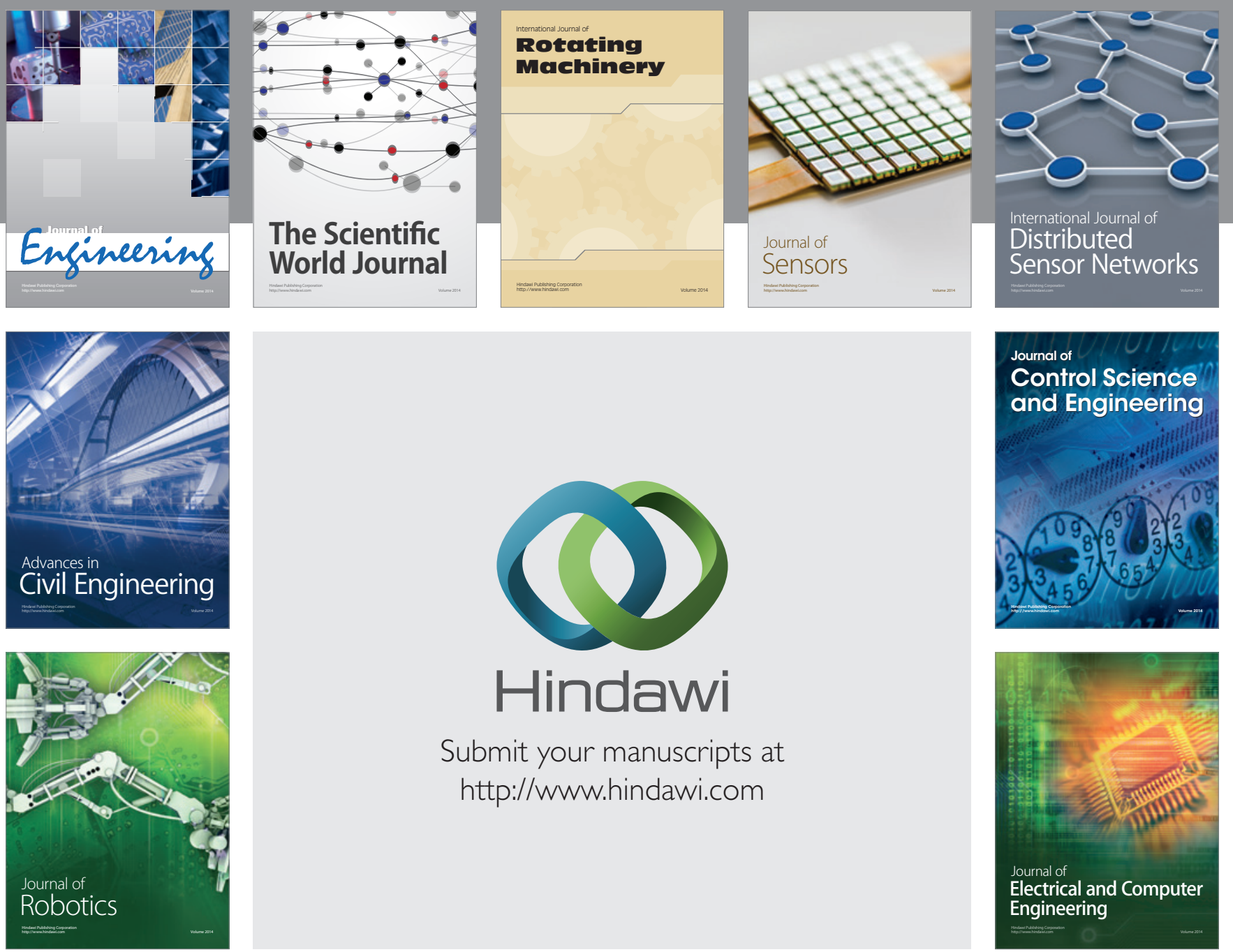

Submit your manuscripts at

http://www.hindawi.com
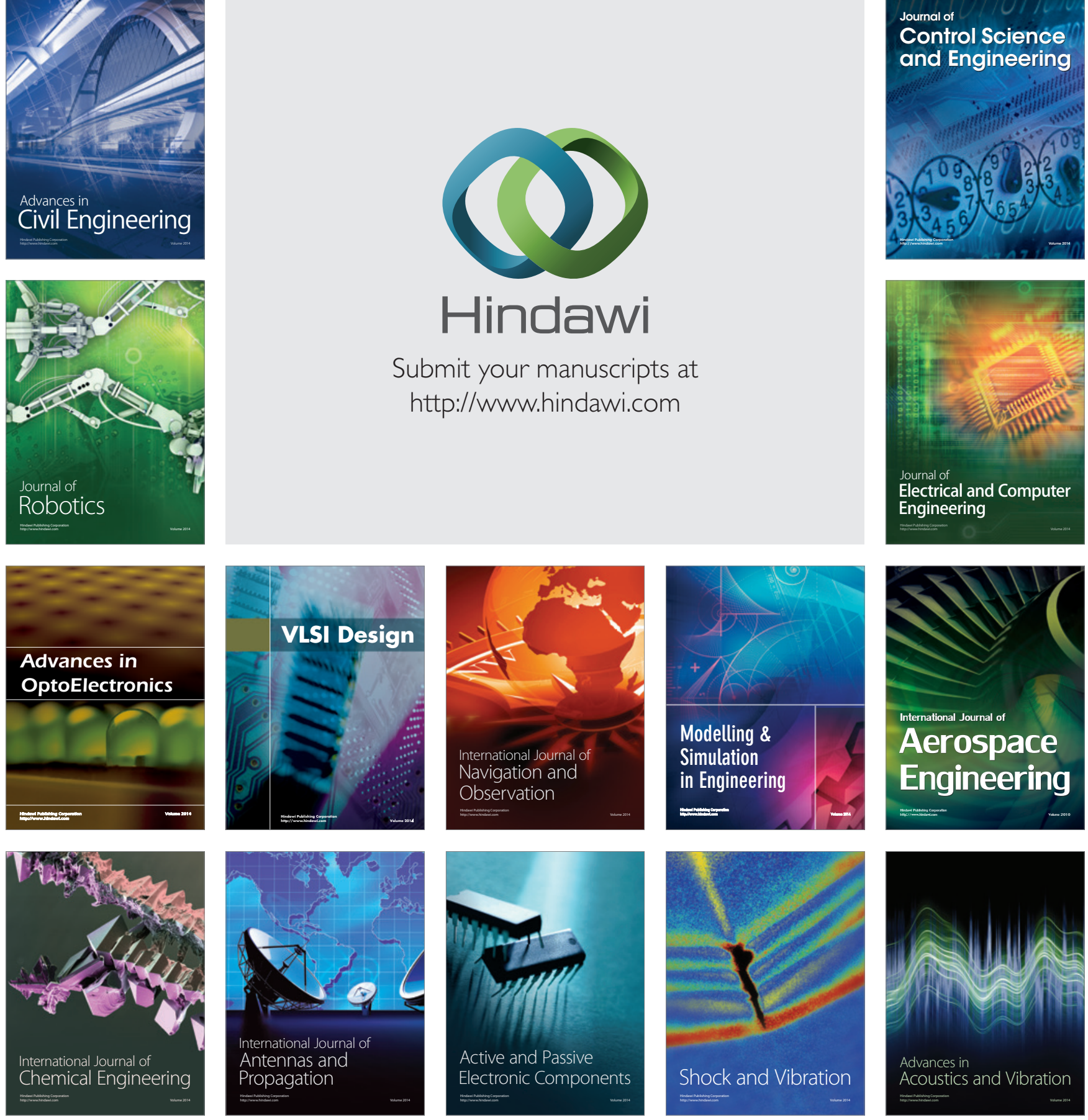